\title{
Digital heritage dissemination and the participatory storytelling project \#iziTRAVELSicilia: the case of the Archaeological Museum of Syracuse (Italy)
}

\author{
Elisa Bonacini ${ }^{1}$, Davide Tanasi ${ }^{1}$, Paolo Trapani $^{2}$ \\ ${ }^{1}$ Department of History, Institute for Digital Exploration (IDEx), University of South Florida. USA \\ 2 Independent Researcher
}

\begin{abstract}
The aim of this paper is to demonstrate how the participatory and crowdsourcing project \#iziTRAVELSicilia could be a key to the dissemination of 3D models on cultural heritage. This project has been recognized as a best practice both in territorial digital marketing and in digital promotion and valorisation through storytelling and crowdsourcing culture. \#iziTRAVELSicilia has already involved thousands of people, producing more than 180 museum and tour audio guides. It has become a real model of participation in the cocreation of cultural values. In this paper we briefly present the project and the case of the Archaeological Museum 'Paolo Orsi' in Syracuse (Italy), as best practice on digital dissemination through platforms such as Google Street View and izi.TRAVEL itself, revealing how this platform has been already largely used for the dissemination both of existing 3D models and for new 3D models, such as those made by USF IDEx for the 'Paolo Orsi' Museum. Specifically, a collection of 26 ancient sculptures and artefacts has been virtualized via laser scanning and digital photogrammetry in a participatory experience of measurement science. The global dissemination of those 3D models through izi.TRAVEL's platform and other alternatives platforms will represent a significant contribute to the digital accessibility of the Museum of Syracuse but also the starting point of a metrological 3D database of ancient Sicilian sculpture generated entirely crowdsourcing.
\end{abstract}

\section{Section: RESEARCH PAPER}

Keywords: crowdsourcing, 3D scanning, photo scanning, Sicily, digital storytelling

Citation: Elisa Bonacini, Davide Tanasi, Paolo Trapani, Digital heritage dissemination and the participatory storytelling project \#iziTRAVELSicilia: the case of the Archaeological Museum of Syracuse (Italy), Acta IMEKO, vol. 7, no. 3, article 7, month 2018, identifier: IMEKO-ACTA-07 (2018)-03-07

Section Editor: Egidio De Benedetto, University of Salento, Italy

Received April 6, 2018; In final form September 5, 2018; Published October 2018

Copyright: (๑ 2018 IMEKO. This is an open-access article distributed under the terms of the Creative Commons Attribution 3.0 License, which permits unrestricted use, distribution, and reproduction in any medium, provided the original author and source are credited

Corresponding author: Davide Tanasi, dtanasi@usf.edu

\section{INTRODUCTION}

Participatory and crowdsourcing approaches in the domain of cultural heritage have become a powerful trend through technological applications [1], [2] thanks to new languages that have developed through the enormous success of social media. These new languages have encouraged the realization and sharing of users' digital content [3], collaborating in "the making of meaning and construction of memories" [4].

Digital technologies, with the potential to offer a great deal of information and production quality, have a real innovative role both in the cultural and touristic domains [5]-[7]. Scholars agree on the importance of the role of digital storytelling [8]-[11] and participatory and crowdsourcing community-based initiatives in enhancing local cultural and touristic attractions, as they offer audiences more freedom and information, especially with reference to context and memorable experiences [12]-[14].

As discussed elsewhere [15], participatory platforms such as izi.TRAVEL, are gaining an important role in supporting local institutions' ability to enhance their own heritage and to involve users in cultural, touristic, and territorial marketing and promotion, by sharing textual and visual information that are considered authentic and trustworthy by consumers. Such process stimulates and supports tourists in planning their experience in a certain region and enjoying cultural and artistic attractions during their stay [16], [17].

In this study, we explore the izi.TRAVEL web platform and app, as used in a pilot project in Sicily, which has made the users' 
experience with Sicilian cultural heritage better overall through storytelling by native people, such as students, teachers, local experts, museum managers and scholars. By linking the storytelling approach to other digital sources already published online, such as virtual tours and 3D models, the platform lets users have a deeper understanding of some artefacts and monuments.

This paper presents the case of the project known as \#iziTRAVELSicilia on social media, launched in May 2016 with the primary goal of filling the great gap in Sicilian cultural heritage and tourist attractions' use of digital communication and development. This participatory process has been able to involve, in two years, more than 3.200 people, from students to museum directors, transforming them into co-creators of more than 180 audio guides, thus promoting their heritage by themselves with the consequent reinforcement of the sense of belonging and local identity.

Among these 183 audio guides, the Archaeological Museum 'Paolo Orsi's audio guide is one of the more complex and information heavy, with 135 schedules organized in 9 collections. The whole museum is browsable via a specific virtual tour launched in 2015 as a pilot project on Google Maps as well as a 360-degree tour of a group of selected objects, while the most important sculptures are enhanced through 3D models linked to a specific collection on Sketchfab. All these elements can play an important role by making the museum into a well-known and enjoyable cultural and tourist attraction [16].

Writers agree that visual digital contents, such as 3D reconstruction, augmented reality, virtual reality, docu-films, fiction, cartoons and so on, allow story-centric narratives to enhance users' understanding of both cultural heritage and historical processes that can build on the "human experience" [18]. After a brief introduction on the platforms involved in this interdisciplinary project (Google Street View, izi.TRAVEL and Sketchfab), the authors will deepen the methods and approach used.

\section{GOOGLE MAPS AND GOOGLE STREET VIEW}

Google Maps and its software Street View are the most important tools Google uses to map the world, improving both the way people use maps and scientific research using satellite imagery, such as geographic studies at a global scale on environmental changes and natural disasters [19]-[21].

Google maps tools have become the fastest and most publicly available tool for archaeological researchers to acquire vertical perspectives on archaeological landscapes and to locate and identify ancient sites or reconstruct 3D models on Earth [22][24]. Google, of course, did not invent anything in the heritage

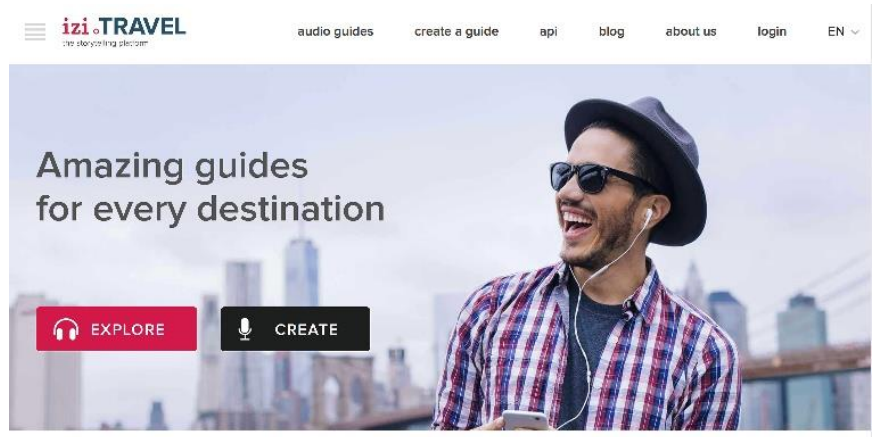

Figure 1. A screenshot of the izi.TRAVEL web-platform homepage. field to provide immersive online panoramas with hyperlinks, but the novelty lies in having taken advantage of linking these technologies to the maps [25].

Furthermore, there is a growing demand for realistic 3D models which could enable increased understanding and popularization of historical-artistic artefacts [26]: the quality of the $3 \mathrm{D}$ reconstructions of environments, monuments, museums galleries and objects has now reached very high levels of precision and many solutions are now available to create $3 \mathrm{D}$ models from panoramic images according to fast and low cost methods [27], [28].

\section{IZI.TRAVEL: A PLATFORM FOR FREE AUDIOGUIDES}

The izi.TRAVEL platform (Figure 1), founded in Amsterdam in 2011 and launched in 2013, with over 3 million uses per month and an annual growth of $100 \%$, has become the most popular free platform based on creativity and storytelling in the world for creating museum audio guides and itineraries [15].

This platform could also be considered as a digital key tool not only for on-site visits but also for planning itineraries and further studies.

By operating on the izi.TRAVEL content management system interface (CMS), both local institutions and users are encouraged to create and manage self-produced cultural digital content by telling their stories. Everyone can freely enjoy every museum audio guides and city audio tours.

A simple text can easily become multimedia, being available in audio mode, with photo galleries and videos (linked to YouTube channels or uploaded by the content provider); it can also become hyper-textual, with the addition of links, making the visit of a museum or the discovery of a city more profound and enjoyable [5]-[7], [15]-[17].

By adding content to the map, the content provider can create georeferenced points of interest and trigger the area, which will be GPS-activated. All the audio guides can be viewed remotely online and on mobile phones via the izi general app (available from App Store, Google play store and Windows Phone store) and by scanning the QR-Codes in situ. The user interface is very simple: visitors can interact with the content over the whole story through navigation menus, preview images or, in the walking mode, directly through GPS position.

The app of a selected museum or tour can also be used in offline mode if downloaded via the download section of the general app.

As shown in Table 1 and in Figure 2, izi.TRAVEL allows users to browse the worldwide audio guides in more than 2200

Table 1. izi.TRAVEL web and app statistics (courtesy of izi.TRAVEL, October 2018).

\begin{tabular}{lr}
\hline \multicolumn{2}{c}{ izi.TRAVEL web and app statistics } \\
\hline Destinations & 2200 \\
City tours & 6800 \\
Museums & 2200 \\
Stories & 250.000 \\
Languages & 54 \\
Countries & 99 \\
Content providers (CP) registered & 20.000 \\
New CP registration per month & 1000 \\
App installs & 3.200 .000 \\
Monthly usage & 4.500 .000 \\
Monthly average usage app & 135.000 \\
Monthly average usage web & 140.000 \\
Yearly usage & 30.000 .000 \\
\hline
\end{tabular}




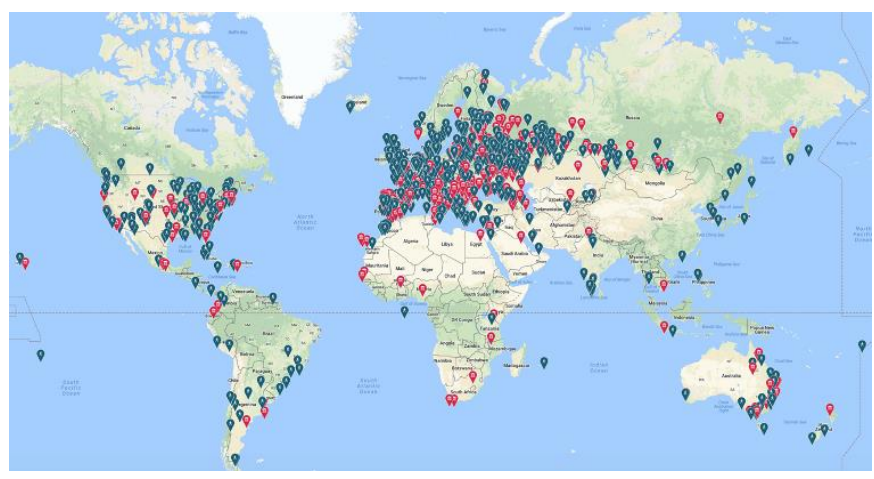

Figure 2. The audio guides dissemination on the izi.TRAVEL platform (courtesy of izi.TRAVEL, May 2018).

museum guides, counting more than 250.000 stories, in 54 languages for a total of 99 countries.

The success of this platform is certainly tied to the new awareness of museums and institutions about the need to adjust their language, including by experimenting with the use of digital storytelling.

\section{SKETCHFAB: A PLATFORM FOR 3D MODELS}

The field of photogrammetry and computer vision techniques for the creation of $3 \mathrm{D}$ models of objects has been characterized in recent years by several innovations [29]: one of the most important among them is the exploitation of Structure for Motion (SfM) techniques [30]-[32].

The web is becoming the main channel of publication and dissemination of visual media, including 3D models, offering a high level of accuracy and ease of use. 3D models should be shared and make available to the public through comprehensive professional software or through specific online viewers [33].

Sketchfab could be considered the most important dissemination platforms for 3D models. Born in 2013, Sketchfab is a global platform to publish, share and discover 3D, VR and AR content, which can also be purchased and sold. Scholars consider Sketchfab "the de-facto standard for publishing 3D content on the web" [34], with more than 2 million uploads.

\section{RESEARCH'S METHODS AT THE “PAOLO ORSI” MUSEUM}

Established with a royal decree as a National Archaeological Museum in 1878, the Museum was first placed inside an historical palace on the island of Ortigia and was directed by the famous archaeologist Paolo Orsi from 1895 to 1934. In 1988 the archaeological collection moved to a new building, in the garden of villa Landolina, fittingly located in the part of the city including the Neapolis Park with its Greek theatre, the altar of Hieron, the Roman amphitheatre and the area of the Catacombs of San Giovanni.

The collection contains artefacts from the Prehistoric, Protohistoric, Greek (sectors A, B and C on the first level), Hellenistic, Roman and Christian periods (sector D and F; the E sector is about to open, with findings from sites in central-eastern Sicily, such as Centuripe, Morgantina, Tindari and so on). Finally, the unique collection of coins and medals from the Archaic to the Medieval periods is located in the basement. With over 20.000 artefacts on display in about $9,000 \mathrm{~m}^{2}$ of exhibition area, the Archaeological Museum 'Paolo Orsi' of Syracuse is one of the most important and richest archaeological museums in Italy.
This paper aims to present three different approaches to the promotion and enhancement of the Sicilian cultural heritage, which have been integrated on the izi.TRAVEL platform in order to offer users, through a single platform, digital content produced in recent years together with the "Paolo Orsi" Museum in Syracuse.

The pilot project on Google Street View was designed by Elisa Bonacini. The \#iziTRAVELSicilia project was created and coordinated by Elisa Bonacini, while the 3D models project was realized by Davide Tanasi in collaboration with Paolino Trapani.

\subsection{The 'Paolo Orsi' Museum pilot project on Google Street View}

Thanks to the agreement between the General Direction of the Regional Department for Cultural Heritage and Sicilian Identity and the European Coordination of Google Business Photo, a pilot project on Google Street View was born in order to increase the realization and enhancement of Sicilian cultural heritage by creating "augmented" virtual tours, through $360^{\circ}$ virtual tours of objects displayed in museum cases and information provided by schedules [35]-[36].

The project, in the form of a Street View virtual tour, was carried out in close collaboration with the staff of the Museum.

A large photographic survey undertaken by Gianfranco Guccione began in August 2014, with the aim of mapping all the areas of the first and second levels open to visitors.

A total of 3.924 photographs to cover $327360^{\circ}$ virtual tours were taken using a mobile station consisting of a reflex camera with fisheye type camera lens on tripods with a panoramic head. The light in the different museum's sectors required adjusting the brightness each time. In the winding path of the museum, windows would often reflect one another, and precautions were taken to avoid those refractions whenever possible.

Thanks to this project, the "Paolo Orsi" pilot project "is the first archaeological museum in the world - needless to say, the first museum in Sicily - entirely browsable on Google Maps platforms with a virtual tour in all exhibition halls and $360^{\circ}$ virtual tours with integration of captions and description of artworks" [35] (Figure 3).

The "Paolo Orsi" Museum is entirely browsable in $360^{\circ}$ in a traditional Street View since August 2014, for the first floor and the second floor and are connected to each other by arrows.

The novelty of the "Paolo Orsi" project consists in the fact that "the project provided the opportunity to carry out $360^{\circ}$ virtual tours of some exposed archaeological finds, like an augmented virtual tour, certainly innovative compared to what has been previously seen on Google's platforms" [35].

The augmented virtual tour, where one can view all additional items (virtual tour of the objects, maps, captions, info etc.), is browsable.

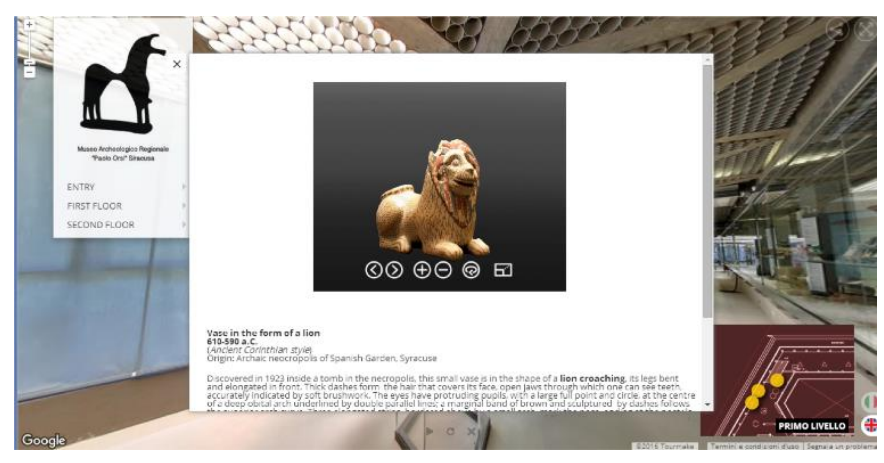

Figure 3. A screenshot of the $360^{\circ}$ virtual tour of one selected object from the "Paolo Orsi" Museum virtual tour. 


\section{2. \#izi.TRAVELSicilia: a participatory storytelling approach for cultural heritage dissemination}

A large-scale regional project was launched on the izi.TRAVEL platform on May 2016 thanks to an annual grant, financed by izi.TRAVEL itself, and to a general agreement between the Regional Department of Cultural Heritage and Sicilian Identity and the University of Catania [37].

The project aimed to fill the gap in communication and cultural and touristic promotion of Sicilian heritage and territories, under a single regional-level management, coordination and support. Under this coordination, a network of storytellers was created, embracing the common idea to promote culture and territories through a bottom-up and disseminated process, involving many other regional and local authorities, institutions, cultural associations, schools, and universities (all the "heritage communities" cited by the Faro Convention) to guarantee the common right to cultural heritage [38].

The project was soon transformed into a participatory process, without distinction of prominence or importance of heritage sites, but with the common aim of enhancing them: at the beginning, only seven audio guides were available in the whole of Sicily; now there are 183.

Digital storytelling has been the key focus of this project: in all the published audio guides, the recounting of history took place in a narrative mode. The storytelling approach adopted for \#iziTRAVELSicilia, well described elsewhere [37], aimed at explaining a monument, a place, a landscape or a work of art according to the concepts of knowledge, languages and creativity [39].

All the people (about 3,200) who were involved become "digital Ciceroni", or storytellers of their own heritage, ranging from elementary school children to high school and university students to the museum managers themselves.

In some cases, the storytelling approach adopted for the project can be described as a sort of digital theatrical storytelling, where some storytellers interpreted stories and characters. One of the projects worth mentioning, for its high level of educational and inclusive content, is one of the three audio guides made for the Archaeological Park of Selinunte and Cave di Cusa by the students of the Comprehensive Institute "Lombardo Radice Pappalardo" in Castelvetrano (Trapani). Students from all the Primary School classes produced Temples and Metopes - Children's Guide (I templi e le metope - Guida per bambini), also published in English. In the meanwhile, all the Secondary School classes worked on two audio tours: Children from Selinunte tell (I piccoli Selinuntini raccontano) and Little stonemasons tell the Cusa Quarries (I piccoli scalpellini raccontano le Cave di Cusa). The children, embodying Greek children from Selinunte, tell the cultural heritage of their town and the nearby Cusa Quarries from which they extracted the building material. Students of 66 classes worked on this project, for about 900 children, followed by over 50 teachers. 66 children gave different voices to each board (in general, people who contributed to the creation of audio guides are always credited in the summaries and even in the boards, with their first and last name). Among these voices, one belongs to a child suffering from selective mutism preventing her from speaking in the classroom. Nevertheless, she succeeded in speaking at home pushed by her will to contribute to the project.

The framework briefly provided here only summarizes the results so far achieved, described more deeply elsewhere [37].

Thanks to this project, Sicily has become one of the few regions in the world to experience such a great participatory, democratic, horizontal and co-creative process in such a

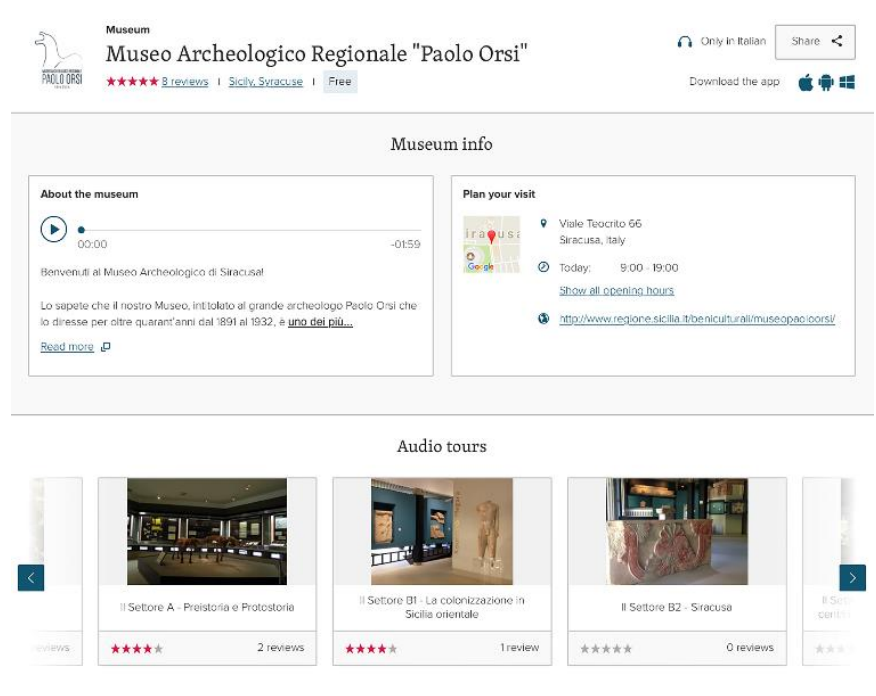

Figure 4. A screenshot of the "Paolo Orsi" Museum audio guide on the izi.TRAVEL platform.

coherent and coordinated way, with the only aim to promote and enhance shared cultural heritage. On the same platform, without distinction of ownership and size, small and large museums and different itineraries on the territory are all together described.

So far, the collaboration with all the Sicilian Cultural Heritage institutions has been extensive. In many cases, the narrative voices are those of the museum staff, who give their voice to tell the heritage they love and protect every day.

One example is exactly that one of the "Paolo Orsi" museum audio guide (Figure 4), where all the archaeologists working there introduce every section of the museum and every work of art, telling all of their underlying stories. As just said, the audio guide is organized into nine collections with 135 schedules inside them.

This audio guide used the digital storytelling approach as a specific tool for the democratization of cultural content [9], [11], [39]-[40].

Narratives of complex context, such as those of an archaeological museum, require complex work, made with museum staff, for extracting the universe of stories that the sites, phases, and objects themselves enclose.

The archaeological museum's staff became storytellers, always addressing the users, stimulating their curiosity, giving them questions which they soon answer, simplifying - but not trivializing - the concepts, the historical epochs, and the objects. They took for granted that users do not know anything about archaeological contexts, ancient colonies and prehistoric or historical phases: the multimedia audio guide can help them to understand and deepen their knowledge.

\subsection{The dissemination of $3 \mathrm{D}$ reconstructions and virtual tours through \#izi.TRAVELSicilia}

The logic itself of the izi.TRAVEL multimedia platform favours ease of use and familiarity of approach, allowing the user to browse and view content simultaneously.

Contexts, monuments, works of art, characters and so on become themselves narrative, using visual and always evocative support, with the core idea being to fit hyper-texts with images, videos, and, in the case of archaeological contexts, reconstructive $3 \mathrm{D}$ videos or 3D models, such as in the case of "Paolo Orsi" audio guide that we are going to introduce.

The real productive process involved a deep reworking of knowledge and scientific communication, choosing a descriptive, simple, and appealing style. The aim of this approach was "to 


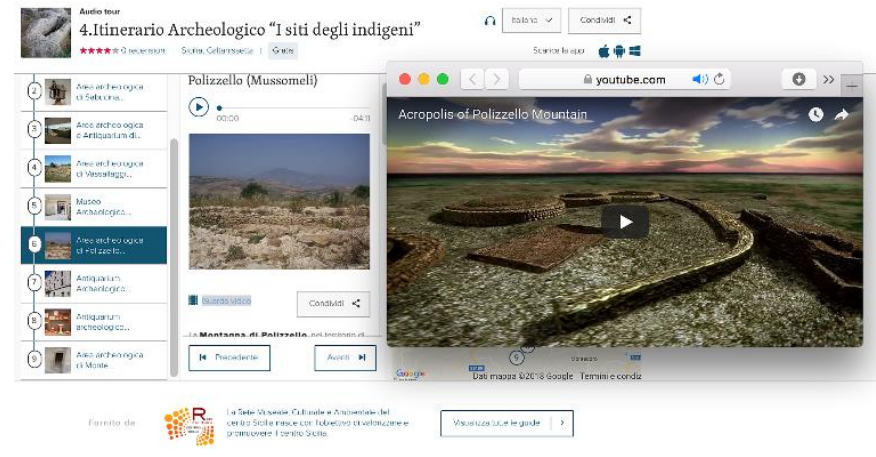

Figure 5. A screenshot of the video on YouTube with the Polizzello 3D virtual reconstruction.

find a solution how to engage visitors in a story by maintaining story-coherency and preserving an uninterrupted feeling of a story flow, while also adjusting the story to better match visitor characteristics and needs" [41] and, in addition, their different interests. An appealing and creative style was created, with the primary goal to make both the content and the stories as attractive as possible, while always respecting the relationship between creativity and reliability.

The izi.TRAVEL platform has also been easily used to disseminate $3 \mathrm{D}$ content to better understand spatiality and to contribute to deepen storytelling of an archaeological context.

Virtual reconstructions of ancient monuments already on YouTube have been used as visual insights for a better understanding of ancient architecture through 3D virtual reconstructions (e.g. in the case of the Greek Theatre and Temples of Syracuse, the Greek-Roman Theatre and the Amphitheatre of Catania, the Roman Theatre of Taormina, the ancient acropolis of the indigenous site of Polizzello in central Sicily (Figure 5), or the Temple of Jupiter in Agrigento, just to cite some examples) or 3D models of sites (such as 3D models of some rooms and details of the Roman Villa of Durrueli, near Agrigento: [42], [43] (Figure 6).

The izi.TRAVEL platform was also used to disseminate online virtual tours, such as that of the Roman "Achillean" Baths in Catania, those of some churches in Piazza Armerina, the Google Collection project on the Agrigento Valley of the Temples and the Google Street View pilot project around the "Paolo Orsi" Museum, which users can browse directly from the summary of the izi.TRAVEL audio guide.

\subsection{The dissemination of 3D models: the "Paolo Orsi" museum}

In the specific case of the "Paolo Orsi" museum audio guide, a Sketchfab collection of 3D models of selected artefacts were linked to their schedules.

Between 2010 and 2016, the academic staff of IDEx undertook an interdisciplinary educational program at the Archaeological Museum of Syracuse in which numerous Italian and American undergraduate students participated as part of onsite classes and internships. The program was fostered by University of Catania's Archeomatica Project, a pioneering collaborative research project on Digital Archaeology, which is still active. Between 2010 and 2016, Computer Science undergraduate students from the Department of Mathematics and Computer Science for the University of Catania participated in an internship on Digital Tools for Cultural Heritage at the Museum of Syracuse. Subsequently, between 2014-2016 American undergraduate students from The College of Global Studies of Arcadia University carried out a series of on-site classes and lab activities at the Museum as part of the course "3D
Modelling for Archaeology and Cultural Heritage". This last activity was also part of the Museum's education program "Progetto Scuola-Museo" in which Italian students from local high schools were also involved. Under the supervision of IDEx academic staff, throughout the six years of the program students employed several 3D techniques to virtualize 26 archaeological artefacts ideally representing the entire collection of the Museum of Syracuse from Prehistory to the Roman period, including nonClassical statues such as the Sikel enthroned goddess from Poggio dell'Aquila and the Kourotrophos of Megara Hyblaea and the Egyptian statue of the scribe Petamenofi. Students were trained in the use of low cost 3D scanners and in digital photogrammetry and subsequently the use software for the processing of the $3 \mathrm{D}$ data.

The project had both educational and research goals. With respect to education, digital technologies were used to connect students to ancient artefacts showing how profitable the study of such artefacts can be when producing $3 \mathrm{D}$ models and interacting with those digital replicas. The second goal was to test and compare three different and popular low-cost 3D scanners employing un-experienced users to make an assessment on uncertainty and repeatability. This assessment would have played an important role for a long-term alternative goal that of using the group of $3 \mathrm{D}$ models of statues produced as the starting point of an online metrological 3D database meant to be progressively populated via crowdsourcing.

Low cost devices largely used by students to virtualize small and medium size artefacts include the Structure Sensor produced by Occipital (Figure 7), and the Microsoft Kinect for XBOX 360 (Figure 8). Both are hand held scanners that use infrared structured light for 3D estimation and are quite popular among archaeologists [44], [45]. Specifically, they project an infrared grid of points whose deformation provides depth information. Such scanners do not work well with sunlight due to solar radiation of infrared light that interferes with the grid pattern emitted by the scanner. Hence, they are ideal to be used in an indoor environment.

For 3D scanning more detailed and small artefacts, a low cost desktop device largely used in physical anthropology [46], such as the NextEngine triangulation laser scanner was used with an accuracy of 0:1 $\mathrm{mm}$ in Macro Mode (Figure 9).

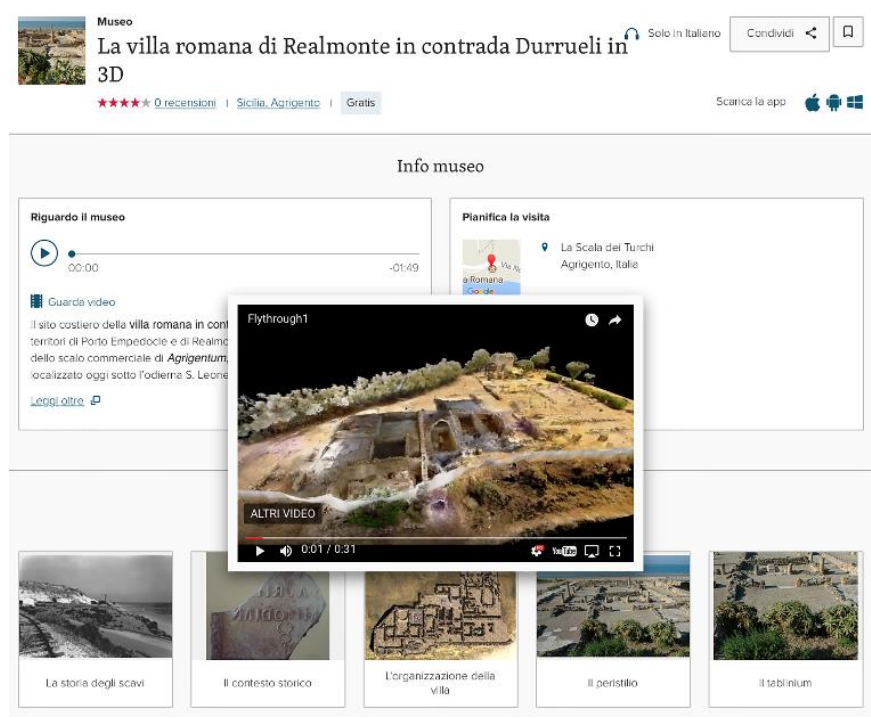

Figure 6. A screenshot of the video on YouTube of the 3D model of the Roman Villa of Durrueli. 


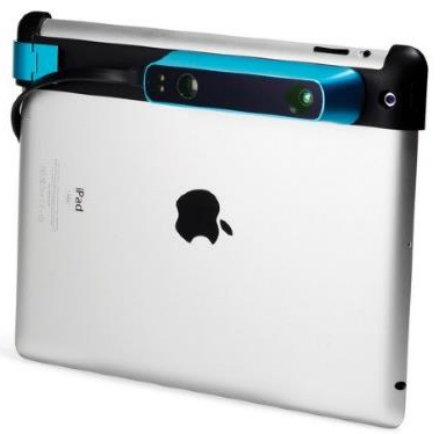

Figure 7. Structure Sensor clipped onto an iPad.

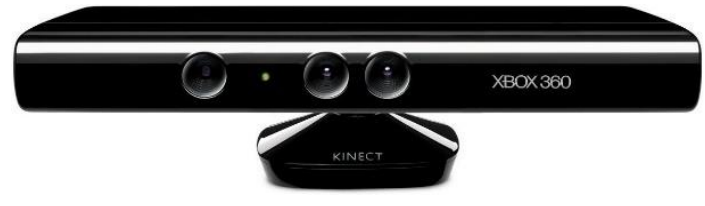

Figure 8. Microsoft Kinect (360).

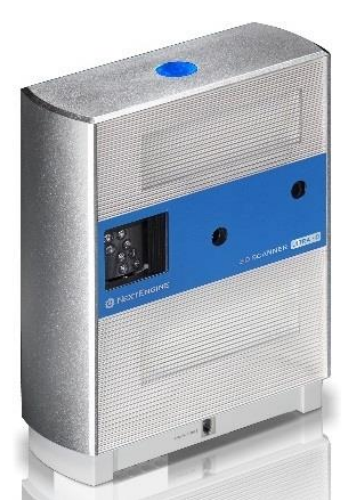

Figure 9. NextEngine triangulation laser scanner.
In certain cases, digital photogrammetry has been also used, employing a 24-megapixel Nikon D7100 with an 18-140mm lens, to create photorealistic textures, which were mapped onto the meshes. Digital photogrammetry is becoming increasingly popular among field archaeologists and curators in museums for its low costs and high-quality results [47].

The software employed for the processing of the 3D scanning data has been primarily MeshLab (Figure 10), a powerful crossplatform open source mesh processor [48], while processing the data from digital photogrammetry was done with an educational licensed version of Agisoft Photoscan (Figure 11). The students at the end of the activity carried out the preliminary processing of the data. Subsequently, IDEx academic staff finalized all of the models.

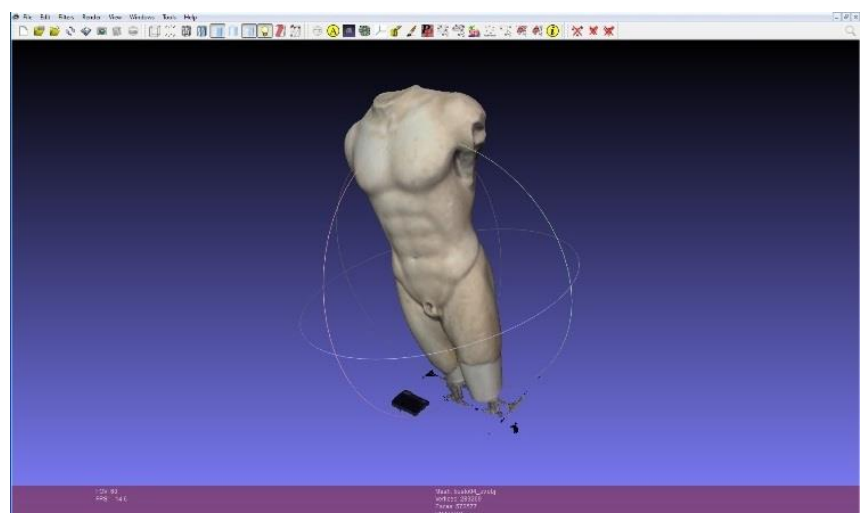

Figure 10. Processing phase with MeshLab.

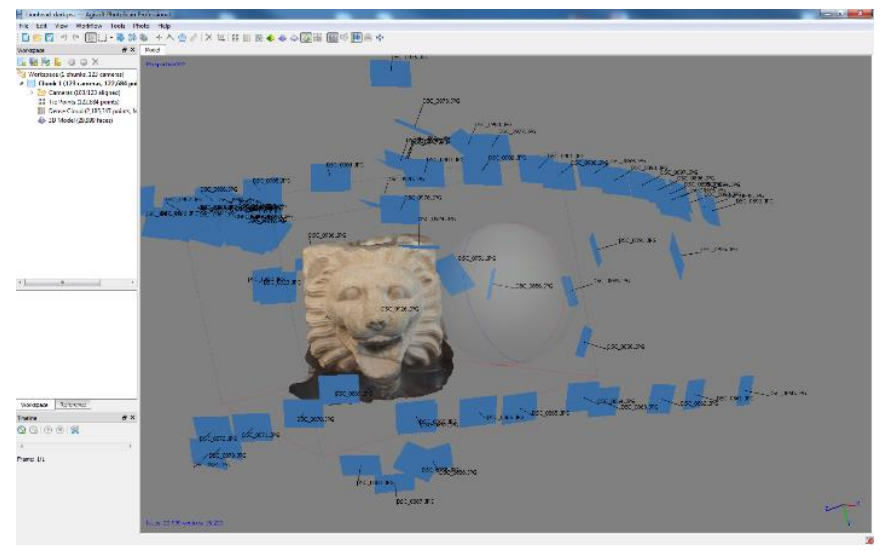

Figure 11. Processing phase with Agisoft Photoscan.

\section{RESULTS}

Considering that students conducted the entire exercise of $3 \mathrm{D}$ scanning and photo scanning of the 26 artefacts with only basic training as part of an educational program in digitization of cultural heritage, the results obtained are satisfactory.

Although comparative assessments on performances and accuracy of Structure, Kinect and NextEngine have been already undertaken $[48,49,50]$, experiments were carried out virtualizing the same artefacts with the three devices and with the same lighting conditions. Specifically, limestone, marble and terracotta sculpture were chosen for the test. Afterwards, the results were evaluated using Meshlab, comparing the number of vertices and faces to assess resolution and using Meshlab's measuring tool for metrological comparisons. Structure and Kinect turned out very effective in capturing statues with matt surfaces, especially at close range. Using the results produced by the triangulation laser scanner NextEngine as a reference, the Occipital Structure proved to have an accuracy of $0.5 \mathrm{~mm}$ at $40 \mathrm{~cm}$ of range, while the Microsoft Kinect had a more variable accuracy of 2.5 to 5.8 $\mathrm{mm}$ at $50 \mathrm{~cm}$.

The lighting conditions inside of the Museum, a combination of natural and artificial lights with spotlights on certain artefacts and shady areas in the corners of the rooms, endangered in many instances the quality of the textures to the extent that in eight cases it was not possible to reconstruct them, leaving the models un-textured. In order to create a more uniform light environment four 90 x $180 \mathrm{~m}$ reflecting panels were placed on site and paired up with a system of YONGNUO wireless led lights.

Table 2 details item by item the technique used to virtualize the artefacts and the related technical features of their 3D models. With respect to quality of the meshes, it ranges from models with 60.624 faces to those with 7.686.926 faces. In general, structured light scanners such as the Structure and Kinect cannot produce very high quality meshes like a laser scanner such as the NextEngine can. However, the overall outcomes are acceptable even considering that, for $3 \mathrm{D}$ printing purposes, a 3D model must be decimated to 100.000 faces anyway.

All but seven 3D models (the Maltese type pedestal cup, the juglet from Sant'Angelo Muxaro, the young boy from Achradina, the non-Hellenic inscription from Mendolito di Adrano, the torso from Achradina, the head of Augustus and the, 'Dama Flavia') were linked on izi.TRAVEL. The links point to the digital platform of Sketchfab, where a dedicated collection, here listed in Table 3, has been created on the IDEx channel (Table 3, Figure 12). 
Table 2. List of the artefacts virtualized with related technique employed and technical features of the 3D models (v.: vertices, f.: faces,).

\begin{tabular}{|c|c|c|c|c|}
\hline Object & Method & \multicolumn{3}{|c|}{ 3D model features } \\
\hline \multicolumn{5}{|l|}{ Pre/Proto-historic } \\
\hline Lithic panel from tomb 31 of Castelluccio (inv. no. 8922) & 3D scanning (Kinect) & v. 920.267 & f. 1.823 .188 & un-textured \\
\hline Lithic panel from tomb 34 of Castelluccio (inv. no. 8971) & 3D scanning (Kinect) & v. 801.572 & f. 1.603 .131 & un-textured \\
\hline Maltese type pedestal cup (inv. no. 11246) & 3D scanning (NextEngine) & v. 192.733 & f. 385.462 , & textured \\
\hline Juglet from Sant'Angelo Muxaro necropolis (inv. no. 46410) & digital photogrammetry & v. 108.677 & f. 216.940 & textured \\
\hline \multicolumn{5}{|l|}{ Archaic } \\
\hline Kouros of Megara Hyblaea (inv. no. 49401) & 3D scanning (Kinect) & v. 199.017 & f. 398.037 & textured \\
\hline Kouros of Leontinoi (inv. no. 26624) & 3D scanning (Structure) & v. 289.269 & f. 572.577 , & textured \\
\hline Young boy from Achradina (inv. no 706) & 3D scanning (Structure) & v. 30.314 & f. 60.624 & textured \\
\hline Goddess of Grammichele (inv. no. 23166) & 3D scanning (Kinect) & v. 133.570 & f. 265.758 & textured \\
\hline Goddess from Poggio dell'Aquila (inv. no 14366) & 3D scanning (Structure) & v. 258.608 & f. 488.110 & textured \\
\hline Kourotrophos of Megara Hyblaea (inv. no. 53234) & 3D scanning (Kinect) & v. 978.738 & f. 1852081 & textured \\
\hline Egyptian statue of scribe Petamenofi (inv. no. 288) & digital photogrammetry & v. 45.121 & f. 900.00 & textured \\
\hline Golden ring with cow and calf from Sant'Angelo Muxaro (inv. no. 45905) & digital photogrammetry & v. 979.865 & f. 1.959 .730 & textured \\
\hline Golden ring with a wolf from Sant'Angelo Muxaro (inv. no. 46517) & digital photogrammetry & v. 447.938 & f. 895.876 & textured \\
\hline Milestone from Naxos (inv. no 104387) & digital photogrammetry & v. 2.509 .615 & f. 4.117 .051 & textured \\
\hline Non-Hellenic inscription from Mendolito di Adrano (inv. no. 96962) & 3D scanning (NextEngine) & v. 462.004 & f. 999.999 & textured \\
\hline \multicolumn{5}{|l|}{ Classical } \\
\hline Torso from Archadina (inv. no 6422) & 3D scanning (Kinect) & v. 145.514 & f. 371.184 & textured \\
\hline Satyr-telamon from Neapolis district (inv. no 916) & 3D scanning (NextEngine) & v. 523.042 & f. 1.046 .080 & un-textured \\
\hline Lion gutter from Euryalos castle (inv. no. 102283) & digital photogrammetry & v. 152.200 & f. 275.091 & textured \\
\hline \multicolumn{5}{|l|}{ Hellenistic } \\
\hline Venus Landolina (inv. no. 694) & 3D scanning (Kinect) & v. 466.731 & f. 402.623 & textured \\
\hline Asclepius from Castello Maniace (inv. no. 737) & 3D scanning (NextEngine) & v. 3.870 .723 & f. 7.686 .926 & un-textured \\
\hline Statue of the 'Fisherman' (inv. no. 49364) & digital photogrammetry & v. 89.574 & f. 81.147 & textured \\
\hline Head of Priapus (inv. no. 97227) & 3D scanning (NextEngine) & v. 613.601 & f. 1.227 .158 & un-textured \\
\hline \multicolumn{5}{|l|}{ Roman Imperial } \\
\hline Head of Augustus from Centuripe (inv. no. 50698) & 3D scanning (NextEngine) & v. 853.005 & f. 1.693 .660 & un-textured \\
\hline 'Dama Flavia' (inv. no. 697) & 3D scanning (NextEngine) & v. 176.806 & f. 352.880 & un-textured \\
\hline Roman magistrate (inv. no. 698) & 3D scanning (Structure) & v. 480.326 & f. 960.664 & un-textured \\
\hline Sarcophagus of Adelphia (inv. no 864) & digital photogrammetry & v. 891.657 & f. 1.783 .300 & textured \\
\hline
\end{tabular}

Thanks to izi.TRAVEL CMS, links have been created directly on the selected schedules, inviting the user to discover the 3D model of the object. A new panel opens the Sketchfab model and the user can directly browse the model via both the web and the mobile app. This is a new approach to view and communicate heritage and reveals how creative the relationships between cultural institutions and local communities can be by creating new cultural experiences for end-users and new forms of cultural dissemination.

In the case of the Lion gutter, the 3D model was linked to the Euryalos Castle audio guide, which is also available in Spanish.

In the case of the Kouros of Lentini, the 3D model was also linked to the corresponding schedule in the Castello Ursino Civic Museum in Catania, where the head of this statue (named the Biscari head, after its discoverer) is displayed. The 3D model of the Biscari head has also been linked to the corresponding

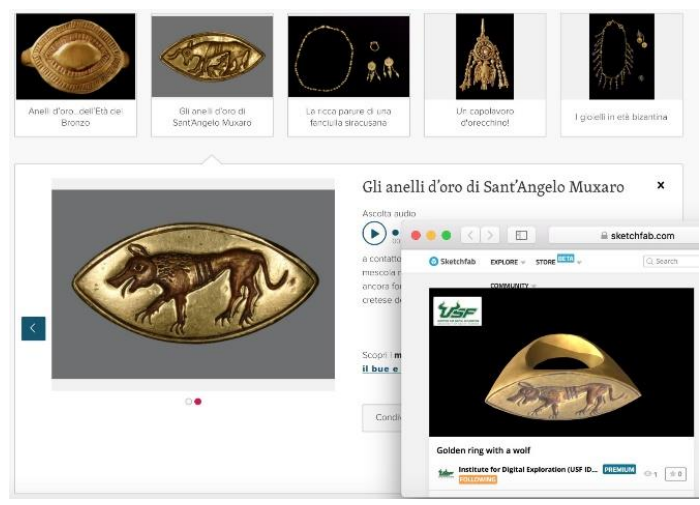

Figure 13. A screenshot of the schedule about the golden rings from Sant'Angelo Muxaro on izi.TRAVEL web-platform with the corresponding 3D model on Sketchfab. 
Table 3. List of the 3D models and the direct links to IDEx's digital collection of the Archaeological Museum of Syracuse 'Paolo Orsi' on Sketchfab.

\begin{tabular}{|c|c|}
\hline 3D model & 3D model link on IDEx Sketchfab collection \\
\hline Lithic panel from tomb 31 of Castelluccio & https://skfb.ly/6xSGM \\
\hline Lithic panel from tomb 34 of Castelluccio & https://skfb.ly/6xSGQ \\
\hline Maltese type pedestal cup & https://skfb.ly/6xSGt \\
\hline Juglet from Sant'Angelo Muxaro necropolis & https://skfb.ly/6xSGE \\
\hline Kouros of Megara Hyblaea & https://skfb.ly/6wWVE \\
\hline Kouros of Leontinoi & https://skfb.ly/6wWVz \\
\hline Young boy from Achradina & https://skfb.ly/6vG9r \\
\hline Goddess of Grammichele & https://skfb.ly/6wWVv \\
\hline Goddess from Poggio dell'Aquila & $\underline{\text { https://skfb.ly/6wWVu }}$ \\
\hline Kourotrophos of Megara Hyblaea & https://skfb.ly/6wWVD \\
\hline Egyptian statue of scribe Petamenofi & https://skfb.ly/6wxNC \\
\hline Golden ring with cow and calf from Sant'Angelo Muxaro & https://skfb.ly/6xSHT \\
\hline Golden ring with a wolf from Sant'Angelo Muxaro & https://skfb.ly/6xSHW \\
\hline Milestone from Naxos & $\underline{\text { https://skfb.ly/6xSI7 }}$ \\
\hline Non-Hellenic inscription from Mendolito di Adrano & https://skfb.ly/6xSGV \\
\hline Torso from Achradina & https://skfb.ly/6wWVB \\
\hline Satyr-telamon from Neapolis district & https://skfb.ly/6xSHO \\
\hline Lion gutter from Euryalos castle & https://skfb.ly/6wWVy \\
\hline Venus Landolina & https://skfb.ly/6wWVC \\
\hline Asclepius from Castello Maniace & https://skfb.ly/6wWVw \\
\hline Statue of the 'Fisherman' & https://skfb.ly/6wWVF \\
\hline Head of Priapus & https://skfb.ly/6wWVx \\
\hline Head of Augustus from Centuripe & https://skfb.ly/6xSHQ \\
\hline ‘Dama Flavia' & https://skfb.ly/6xSGY \\
\hline Roman magistrate & https://skfb.ly/6xSH6 \\
\hline Sarcophagus of Adelphia & $\underline{\text { https://skfb.ly/6xSGG }}$ \\
\hline
\end{tabular}

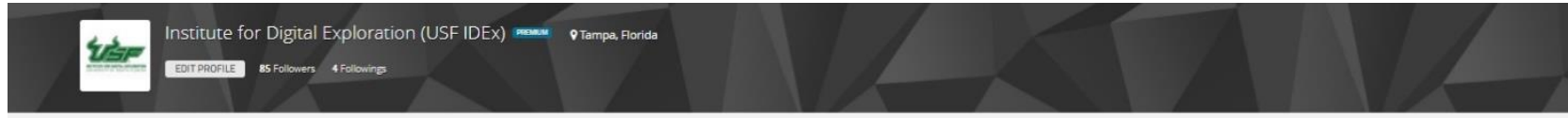

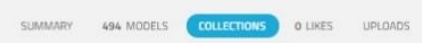

Museo Archeologico Regionale di Siracusa, Italy

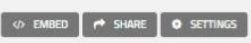
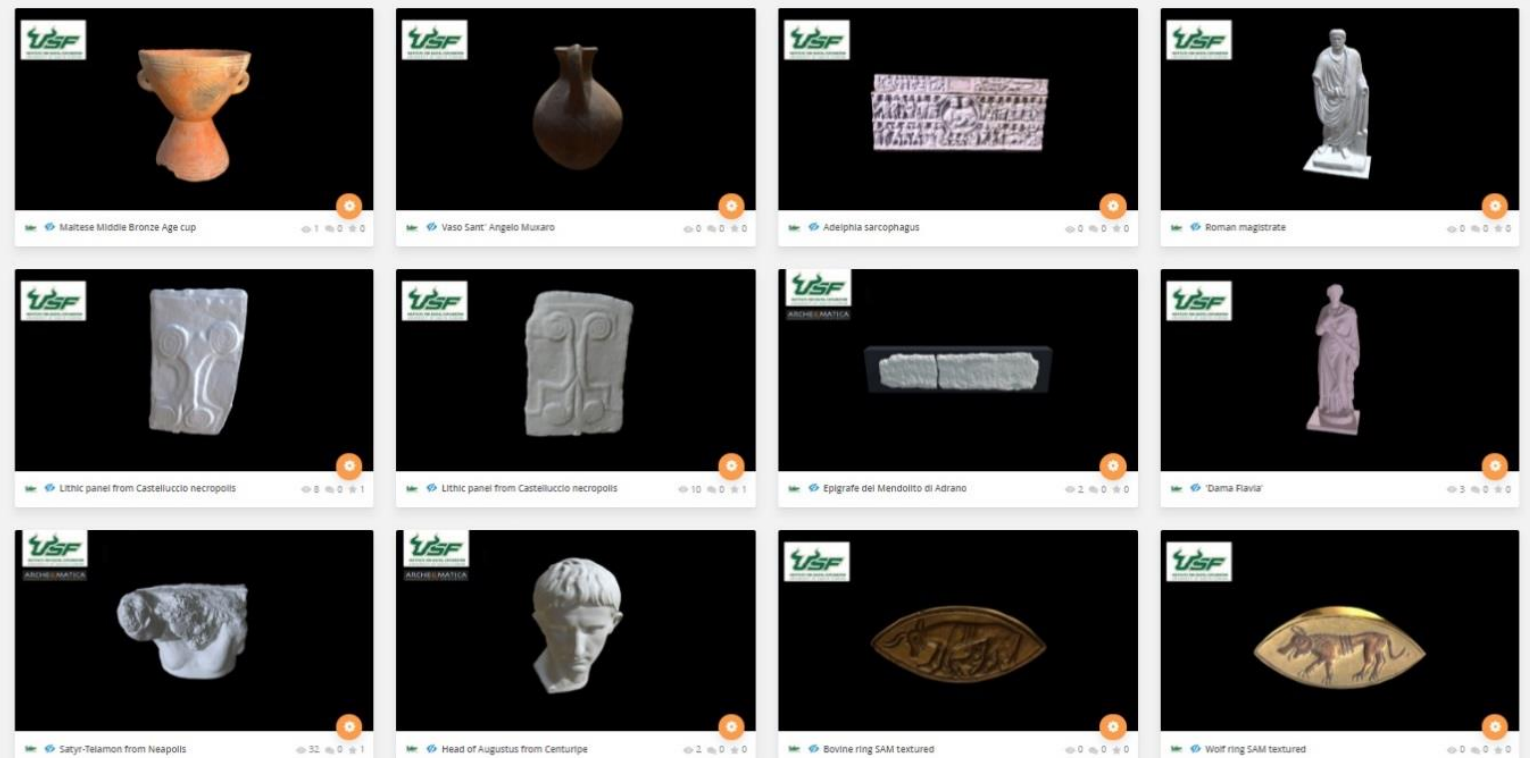

Figure 12. IDEx's digital collection from the Archaeological Museum 'Paolo Orsi' of Syracuse, on Sketchfab. 
schedule on the "Paolo Orsi" museum audio guide, and a digital reconstruction of this statue has been created and linked on both the audio guides, thus allowing users to digitally access and understand this unique piece of archaic sculpture split between two different collections.

For the first time, remote and mobile users can enjoy a piece of art, such as one of the Golden rings from Sant'Angelo Muxaro (Figure 13), by browsing the 3D model and by observing the accurate work of the animals on the rings, as if the users were turning the rings between their fingers.

These are only brief examples of how the izi.TRAVEL platform can be useful to cross-link digital resources, giving them much more visibility, to enhance an end-user's full experience of artworks. Some final feedback, which users directly gave to the audio guides on the platform (out of more than 180 comments), appear to appreciate this kind of digital cultural communication, by integrating storytelling with $3 \mathrm{D}$ models.

Furthermore, the "Paolo Orsi" museum audio guide is connected to many other resources on izi.TRAVEL itself, creating a digital network between all these existing digital resources. All the 3D models on the IDEx digital collection on Sketchfab of the Archaeological Museum 'Paolo Orsi' of Syracuse are public and accompanied by a minimal set of metadata.

\section{DISCUSSION}

The participatory virtualization project of the ancient artefacts of the archaeological museum of Syracuse proved the efficacy of using low cost scanners as fast and accurate tools to document cultural heritage with satisfactory accuracy and produce invaluable teaching tools and ready-to-disseminate high impact visual outcomes.

The metrological survey via 3D scanners provided new data, which helped curators to correct previous erroneous measurements of certain objects in the museum records, and the online availability of the 3D models will certainly be beneficial for scholars interested by this aspect of the research and not able to have direct access to the objects in the museum.

Occipital Structure and Microsoft Kinect proved to be extremely versatile, easy to use, precise $3 \mathrm{D}$ scanners, perfectly suited for participatory museum experience where curators could involve the public or student interns.

The use of a custom-built photographic studio with wireless led light and reflective panels was instrumental to mitigate the light aberrations, which would have had a more negative impact on the textures.

Ultimately, the incorporation of the 3D models in the izi.TRAVEL platform guarantees a tremendous visibility and could possibly represent an alternative to the current offerings in terms of dissemination platforms and $3 \mathrm{D}$ web viewers. But in order to conceive such a twist to the base idea behind izi.TRAVEL platform it would be necessary to work out an important limitation represented by the current structural lack of funds for the \#izi.TRAVELSicilia imitative. In fact, what has been done so far has accomplished in extreme frugality, revealing, however, how such a model can be replicated in a sustainable way.

We have tried, in many cases, to compensate for the lack of funds that can be used for translation of content by using the voluntary collaboration of native speakers or translators; however, we are well aware that the translation of all audio guides, at least into the English language, would guarantee a visibility to Sicilian heritage the sole use of the Italian language can never guarantee.

The iziTRAVEL platform has been exploited, in this project, to its full potential, implementing storytelling with hypertext links, virtual tours (such as the project on Google Street View) and existing 3D models, already produced with other projects (such as the Schhol project made with Sketchfab), according to the principle of digital content reuse.

The model created in Sicily is, in fact, fully replicable elsewhere, if someone else would try to involve, in a coordinated and controlled way, the heritage communities of a territory. To apply a similar model, it is certainly necessary to start by involving the broadest range of stakeholders, such as local administrations and local communities, such as schools, universities, museum networks, and associations.

\section{CONCLUSIONS}

As shown in Table 4, the \#izi.TRAVELSicilia project has already achieved significant results in terms of general visualization of content and cultural enjoyment of them.

The framework here provided only summarizes the results achieved so far within Sicilian cultural heritage and it can also demonstrate how to add "value to digital cultural heritage collection content" [51, 52].

The \#izi.TRAVELSicilia project, in general, has been able to show how izi.TRAVEL can be an effective tool to foster mass participation and collaborative processes. It has already transformed the Sicilian cultural context by activating a collective, participatory, and co-creative experience to promote the common cultural heritage.

Those who participated in the project, from children to museum directors, have been engaged with their own stories and voices. They became digital witnesses of their own heritage, helping to make it known and enjoyable and, all together, they are already bridging the gap in Sicilian cultural heritage's use of digital technologies.

The \#izi.TRAVELSicilia project provided a new model of collaborative and co-creative partnership giving public cultural institutions and local heritage communities the opportunity to relate to each other and aim at obtaining greater democratic participatory action.

This should be read as the very first phase of an important process. The real goal is both to create more local collaborative

\section{Table 4. \#izi.TRAVELSicilia statistics}

\begin{tabular}{lr}
\hline \multicolumn{2}{c}{ \#izi.TRAVELSicilia statistics } \\
\hline Destinations & 52 \\
City tours & 94 \\
Museums & 84 \\
Stories & 3.000 \\
Content providers (CP) centrally managed & 58 \\
Users involved in the project & 3.200 \\
Videos created by users & 40 \\
Videos of 3D reconstructions linked to YouTube & 25 \\
3D models linked from Sketchfab & 52 \\
Hypertextual content (link to other sources, as web pages or PDF) & 320 \\
Number of visualizations of all contents & 493.000 \\
Audio guides or audio tours fully used & 61.000 \\
Audio guides or audio tours downloaded and used offline & 48.000 \\
Feedback for the audio guides & 183 \\
\hline
\end{tabular}


and co-creative projects about Sicilian heritage, and to expand participation in these projects and their dissemination, including the dissemination of types of digital cultural content, such as what has been done in collaboration with IDEx and its collection of 3D models of artefacts.

Finally, with respect to the metrological value of IDEx's participatory virtualization project and to the next step that could be taken in the research agenda, a new method for the online dissemination of the 3D models will be experimented with, as currently Sketchfab does not provide any measuring tools. For this reason, a new web platform will be created and hosted in an IDEx server with a dedicated web site where the 3Dmodels will be visualized with a 3DHOP based viewer [53], where users would also be able to use measuring and slicing tools. Once this new platform is in place, the 3D content will be re-linked in the izi.TRAVEL platform. In the future, the group of $263 \mathrm{D}$ models could become the starting point of a crowdsourcing measurement project via 3D scanning of the archaeological collections of the museum of Syracuse, after having established clear and precise protocols and guidelines, as an alternative to the more popular idea of the dissemination of digital content for simple cultural enjoyment.

\section{ACKNOWLEDGMENTS}

Thanks to Mrs. Giuseppina Monterosso, from the Archaeological Museum "Paolo Orsi", for her great availability for all these three projects, and to Mr. Gianfranco Guccione, a certified Google photographer, for the pilot project on Google Street View.

\section{REFERENCES}

[1] M. Sani, B. Lynch, J. Visser, A. Gariboldi, 2015, Mapping of practices in the EU Member States on Participatory governance of cultural heritage to support the OMC working group under the same name, EENC Short Analytical Report, June 2015.

[2] Z. Koukopoulos, D. Koukopoulos, 2016, Is user participation feasible in digital cultural heritage environments?, in $2^{\text {nd }}$ CAA-GR conference, 20-21 December 2016, Athens.

[3] D. Van Dijk, 2011, Exploring Heritage in Participatory Culture: The Museum App, in Museums and the Web, Proceedings, Archives \& Museum Informatics, Toronto.

[4] C. L. Liew, 2014, Participatory Cultural Heritage: A Tale of Two Institutions' Use of Social Media, D-lib magazine 20, 3-4.

[5] L. Tallon, K. Walker, 2008, Digital technologies and the museum experience. Handheld Guides and Other Media, Altamira Press: Lanham.

[6] H. Bakhshi, D. Throsby, 2012, New technologies in cultural institutions: theory, evidence and policy implications, International Journal of Cultural Policy, vol. 18, n. 2, 205-222.

[7] M. V. Ciasullo, A. Gaeta, M. Gaeta, G. Monetta, 2016, New modalities for enhancing cultural heritage experience. The enabling role of digital technologies, Sinergie Italian Journal of Management, vol. 34, n. 99, 119-138.

[8] C. Handler Miller, 2008, Digital storytelling, Focal Press, Oxford.

[9] A. Bryan, 2011, The new digital storytelling: creating narratives with new media, Praeger, Santa Barbara.

[10] H. Schoenau-Fog, L. E. Bruni, S. Louchart, S. Baceviciute, 2015 Interactive Storytelling. Proceedings of the 8th International Conference on Interactive Digital Storytelling, ICIDS 2015, Copenhagen Denmark, Novembere 30 - December 4, 2015, Lecture Notes in Computer Science, 9445, Springer International Publishing.

[11] R. M. Van Dyke, R. Bernbeck, 2015, Alternative narratives and the ethics of representation: an introduction, in R. M. Van Dyke,
R. Bernbeck (ed), Subjects and Narratives in Archaeology, University Press of Colorado, Colorado, 1-26.

[12] Y.Kang, J. Stasko, K Luther, A. Ravi, Y. Xu, 2008, RevisiTour: Enriching the tourism experience with user-generated content, in P. O'Connor, W. Höpken, U. Gretzel (eds.), Information and Communication Technologies in Tourism, Springer, Wien, 59-69.

[13] P. O'Connor, 2008, User-Generated content and travel: A case study on tripadvisor.com, in P. O'Connor, W. Höpken, U. Gretzel (eds.), Information and Communication Technologies in Tourism, Springer: Wien, 47-58.

[14] H. Roued-Cunliffe, A. Copeland, 2017, Participatory heritage, Facet Publishing, London.

[15] E. Bonacini, S. C. Giaccone, 2018, Digital participatory tools for territorial promotion: the \#iziTRAVELSicilia case study, in V. Cantino, F. Culasso, G. Racca, Smart Tourism, McGraw Hill Education, Milano, 2018, 417-436.

[16] D. B. Weaver, 2012, Organic, incremental and induced paths to sustainable mass tourism convergence, Tourism Management, 33.5, 1030-1037.

[17] S. Reino, B. Hay, 2016, The use of You Tube as a tourism marketing tool, Tourism Travel and research Association: Advancing Tourism Research Globally, 69.

[18] M. Banks, 2008, Visual anthropology: image, objects and interpretation, in J. Prosser, "Image-based research: a sourcebook for qualitative researchers", Routledge, London, United Kingdom, 2008, 9-23.

[19] L. Yu, P. Gong, 2011, Google Earth as a virtual globe tool for Earth science applications at the global scale: progress and perspectives, International Journal of Remote Sensing, vol. $33 \mathrm{n}$. 12, 3966-3986.

[20] J. Priyono, H. Purwanto, 2007, Google Earth Application to Support Disaster Emergency Response, Jurnal Kebencanaan Indonesia, vol. 1, n. 3.

[21] Q. Chen, L. Jiang, X. Shuai, 2008, The Application of Google Earth in Earthquake Emergency, Earthquake, vol. 1, 121-128.

[22] A. Myers, 2010, Camp Delta, Google Earth and the ethics of remote sensing in archaeology, World Archaeology, Archaeology and Contemporary Society, vol. 42, n. 3, 455-467.

[23] T. Thakuria, T. Padhan, R. K. Mohanty, M. L. Smith, 2013, Google Earth as an Archaeological Tool in the Developing World: An Example from India, The SAA Archaeological Record, vol. 13, n. 1.

[24] B. Lonneville, B. De Roo, C. Stal, B. De Wit, A. De Wulf, P. De Maeyer, 2015, Google Earth and KML as GIS tools for 3D archaeological models, Abstract presented at the CAA 2015. Computer Applications \& Quantitative Methods in Archaeology. 30 March-3April 2015. Siena, Italy.

[25] E. Bonacini, 2017, A survey on the digital enhancement of the archaeological sites on Google and a multimedia pilot project in the Agrigento Valley of the Temples in Sicily (Italy), International Journal of Internet Technology and Secured Transactions, vol. 7, n. $1,28-50$

[26] A. Ippolito, C. Bartolomei, 2015, Management of Cultural Heritage: Bologna Gates, International Journal of Social, Behavioral, Educational, Economic, Business and Industrial Engineering, vol. 9, n. 11.

[27] H. Wen-Kuo, P. Pi-Ling, 2012, 3D Modeling and Application from Panoramic Photography, Paper presented at the 2012 Annual Meeting \& Academic Conference of Taiwan Geographic Information Society. 9-10 December 2012. Taiwan, Taiwan.

[28] J. Li, Y. Sheng, P. Duan, S. Zhang, H. Lv, 2014, Constructing 3D Model Based on Panoramic Images, Advances in Computer Science and its Applications. Lecture Notes in Electrical Engineering, vol. 279, 1061-1065.

[29] E. Baviera Llópez, J. Llopis Verdú, J. Martínez Piqueras, J. L. Denia Ríos, 2019, Heritage Dissemination Through the Virtual and Augmented Realities, in C. Marcos (edited by), Graphic Imprints. EGA 2018, Springer, Cham, 623-632.

[30] F. Remondino, 2011, Advanced 3D recording techniques for the digital documentation and conservation of heritage sites and objects, Changes Over Time, vol. 1, n. 2, 198-214. 
[31] G. Guidi, S. Gonizzi Barsanti, L. L. Micoli, M. Russo, 2015 , Massive 3D digitization of museum contents, in L. Toniolo, $\mathrm{M}$. Boriani, G. Guidi (edited by), Built Heritage: Monitoring Conservation Management, Springer, Cham, 335-346.

[32] L. Inzerillo, C. Santagati, 2016, Crowdsourcing Cultural heritage: form 3D modeling to the engagement of young generations, in M. Ioannides et al. (edited by), EuroMed 2016, 869-879, LNCS 100058.

[33] S. Minto, F. Remondino, 2014, Online access and sharing of reality-based 3D models, SCIRES-It, vol. 4, issue 2, 17-28.

[34] R. Scopigno, M. Callieri, M. Dellepiane, F. Ponchio, M. Potenziani, 2017, Delivering and using 3D models on the web: are we ready?, Virtual Archaeology Review, vol. 8, n. 17, 1-9.

[35] E. Bonacini, 2015, The 'Paolo Orsi' Syracuse Archaeological Museum pilot project. A $360^{\circ}$ tour with Google Indoor Street View, in K. Yetongnon, A. R. Dipanda Chbeir, (edited by), SITIS 2015, Proceedings of the 11th International Conference on SignalImage Technology and Internet-Based Systems, November 23 27, 2015, Bangkok-Thailand, IEEE (The Institute of Electrical and Electronics Engineers, Inc.), Los Alamitos (CA), 2015, 833840.

[36] E. Bonacini, 2015, A Pilot Project with Google Indoor Street View: a $360^{\circ}$ tour of "Paolo Orsi" Museum, in SCIRES-It, vol. 5, issue 2, 151-168.

[37] E. Bonacini, \#iziTRAVELSicilia, a Participatory Storytelling Project/Process: Bottom-Up Involvement of Smart Heritage Communities, in International Journal of Interactive Communication Systems and Technologies, vol. 7, issue 2, 24-52.

[38] L. Zagato, 2015, The Notion of "Heritage Community" in the Council of Europe's Faro Convention. Its Impact on the European Legal Framework, in N. Adell, R. F. Bendix, C. Bortolotto, M. Tauschek (eds), Between Imagined Communities and Communities of Practice. Participation, Territory and the Making of Heritage, Göttingen Studies in Cultural Property, vol. 8, 141-168.

[39] G. De Felice, 2013, Il nuovo allestimento della collezione archeologica della Fondazione Sicilia fra tecnologie e creatività, Archeologia e Calcolatori, 24, 249-263.

[40] E. Bonacini, A. Castorina, 2017, Euryalos Castle and Dionysian walls in Syracuse: creation of a multimedia tour, in A. Ippolito (Ed.), Handbook of Research on Emerging Technologies for Cultural Heritage, IGI Global, Hershey, 387-416.

[41] L. Pujol, A. Katifori, M. Vayanou, M. Roussou, M. Karvounis, M. Kyriakidi, S. Eleftheratou, Y. Ionnidis, 2013. From personalization to adaptivity - Creating immersive visits through interactive digital storytelling at the Acropolis Museum. In Workshop Proceedings of the $9^{\text {th }}$ International Conference on Intelligent Environments (pp. 541-554). Amsterdam, Netherlands: IOS Press.
[42] E. Bonacini, N. Gulli, D. Tanasi, 2016, 3D imaging analysis and digital storytelling for promotion of cultural heritage: the school outreach project of Realmonte, in J. L. Lerma, M. Cabrelles (edited by), Proceedings of Arquelogica 2.0, $8^{\text {th }}$ International Congress Advanced on 3D documentation, modelling and reconstruction of cultural heritage objects, monuments and sites, 5 - 7 September, 2016, València, 392-395.

[43] E. Bonacini, D. Tanasi, 2017, \#iziTRAVELSicilia: a storytelling participatory project, in Proceedings of 3 rd IMEKO International Conference on Metrology for Archaeology and Cultural Heritage, MetroArchaeo 2017, October 23-25, 2017, Lecce, Italy, 589-594.

[44] M. Quintana, F. Zviechvich, B. Castaneda, 2014, 3D Reconstruction of Archaeological Walls Using Kinect. In Proceedings of Euromed 2014 - International Conference on Cultural Heritage, 48-58. LNCS 8740.

[45] A. Barmpoutis, E. Bozia, D. Fortuna, 2015, Interactive 3D digitization, retrieval, and analysis of ancient sculptures, using infrared depth sensors for mobile devices, Lecture Notes in Computer Science (Springer). Proceedings of the $9^{\text {th }}$ International Conference on Universal Access in Human-Computer Interaction. Access to the Human Environment and Culture 2-7 August 2015, vol. 9178, 3-11.

[46] A. Slizewski, M. Friess, P. Semal, 2010, Surface scanning of anthropological specimens: nominal-actual comparison with low cost laser scanner and high-end fringe light projection surface scanning systems, Quartär 57, 179-187.

[47] B. R. Olson, 2016, The Things We Can Do With Pictures: Imagebased Modeling and Archaeology, in E. Walcek, J. Averett, Michael Gordon, D. B. Counts (eds), Mobilizing the past for a digital future, The Digital Press @ University of Dakota, 2016, 237-250.

[48] M. E. Polo, A. M. Felicisimo, 2012, Analysis of Uncertainty and Repeatability of a Low-Cost 3D Laser Scanner, Sensors 12.7, 9046-9054.

[49] M. Kalantari, M. Nechifor, 2016, Accuracy and utility of the Structure Sensor for collecting 3D indoor information, Geospatial Information Science 19, 1-8.

[50] G. Marchal, T. Lygren, 2017, The Microsoft Kinect: validation of a robust and low-cost 3D scanner for biological science, Technical Report, August 2017, DOI: 10.13140/RG.2.2.12069.40167.

[51] P. Cignoni, M. Callieri, M. Corsini, M. Dellepiane, G. Ganovelli, G. Ranzuglia, 2008, MeshLab: an Open-Source Mesh Processing Tool, in V. Scarano, R. De Chiara, U. Erra (eds), Eurographics Italian Chapter Conference, 1-8.

[52] T. Owens, 2013, Digital cultural heritage and the crowd, in Curator: The Museum Journal, vol. 56, n. 1, 121-130.

R. Scopigno, M. Callieri, M. Dellepiane, F. Ponchio, M. Potenziani, 2017, Delivering and using 3D models on the web: are we ready?, Virtual Archaeology Review 8.17, 1-9.

\section{LINKS}

- izi.TRAVEL: https://izi.travel/en

Sketchfab: https://sketchfab.com

"Paolo Orsi" Museum, first floor: https://goo.gl/maps/oagnd8urP1H2, second floor: https://goo.gl/maps/vrpDfuPPgwM2, augmented

virtual tour: http://www.regione.sicilia.it/beniculturali/museopaoloorsi/google-maps/museo-paolo-orsi-Syracuse-primo-piano/index.php

Temples and Metopes - Children's Guide: https://izi.travel/it/7dc4-i-templi-e-le-metope-guida-per-bambini/it

Children from Selinunte tell: https://izi.travel/it/02eb-i-piccoli-selinuntini-raccontano/it

- Little stonemasons tell the Cusa Quarries: https://izi.travel/it/e39e-i-piccoli-scalpellini-raccontano-le-cave-di-cusa/it

"Paolo Orsi" museum audio guide: https://izi.travel/it/4d91-museo-archeologico-regionale-paolo-orsi/it

University of Catania’s Archeomatica Project: $\underline{\text { http://www.archeomatica.unict.it/index.php?lang=english\&page=13 }}$

Structure Sensor produced by Occipital: http://structure.io

- NextEngine triangulation laser scanner: http://www.nextengine.com

- Digital collection of the Archaeological Museum of Syracuse: https://sketchfab.com/cvast/collections/museo-archeologico-regionale-disiracusa-italy

- Euryalos Castle audio guide: https://izi.travel/it/7431-castello-eurialo/it

- Castello Ursino Civic Museum in Catania: https://izi.travel/it/8282-museo-civico-castello-ursino/it 